The Impact of COVID in Higher Education

\title{
Senior interior design students' perceptions about distance learning in the shadow of COVID-19
}

\author{
Samaher A. Fallatah \\ Department of Interior Design Engineering, Prince Sultan University, Riyadh, Saudi Arabia
}

\begin{abstract}
Background: Like many international universities and institutions of higher education that have shifted the entire educational system from the traditional face-to-face education model to distance learning during the COVID-19 pandemic, universities in Saudi Arabia have expended great effort to change the behavior of educators and students to accommodate the transition. This rapid shift has had a significant impact on students, especially in programs such as interior design, in which different practical courses are taught along with the theoretical ones. Therefore, this study aimed to investigate the benefits and challenges senior interior design students experienced while taking their classes online.

Design and Methods: The current paper has adopted a qualitative approach for assessing the data obtained. Semi-structured interview was used to collect all the needed information regarding participants' opinions about distance learning.

Results: Increased time to spend on assignments, reduction of costs to the student, and improvement in achievement of learning outcomes were the three main benefits students reported in their experience of distance learning. On the other hand, technical issues, changes in grade distribution, and changes in project types were identified as student concerns. Although students found many advantages in communicating with others remotely, some issues arose.

Conclusions: Students expressed a preference for the hybrid learning method, or at least for having their exams, juries, and presentations on campus in person, not remotely.
\end{abstract}

\section{Introduction}

The novel corona virus 2019 (COVID-19) pandemic, which was first found in Wuhan, China, ${ }^{1}$ is a new phenomenon that has profoundly affected global public health, ${ }^{2}$ and has changed everyday routines for many individuals. The virus, which mainly affects the respiratory system of individuals, has resulted in a high percentage of fatalities globally. 1,3 The failure to discover an effective medication for treatment, the high fatality rate, and the highly con- tagious nature of this virus, have made the novel coronavirus an international concern. ${ }^{2}$ The World Health Organization (WHO) officially categorized the COVID-19 outbreak as a global pandemic, ${ }^{4}$ and in response, most governmental sectors worldwide, including educational sectors, started taking action to preserve public health, an effort which included finding solutions to accommodate social distancing and cope with this pandemic in the academic environment. ${ }^{2,5,6}$ Saudi Arabia, represented by the Ministry of Education (ME), was one of the first countries to suspend education in public and private schools and universities and any sort of training institutions in response to the confirmed global health crisis, as of March 9, 2020.7

Higher education in Saudi Arabia has implemented different learning strategies in the context of the COVID-19 outbreak to ensure the continuation of the learning process with a desirable quality. It has been confirmed that online learning is the most suitable learning strategy to enable students to continue their education during this pandemic without the human interaction which occurs in traditional face-to-face learning. ${ }^{8}$ Universities in Saudi Arabia have expended great effort to change the practices of educators and students when shifting the entire educational system from the traditional face-to-face education model to distance learning. In addition to the traditional e-learning tools such as videos, audios, chats and PowerPoint, ${ }^{9}$ the Ministry of Education has approved the use of various media platforms such as TV channels, Zoom, Google meet, and Learning Management System (LMS) to bridge the gap between students and instructors. ${ }^{10}$ The m-learning (or mobile-learning) strategy was also adopted as a means to facilitate communication between students and their peers or instructors. M-learning facilitates interaction via personal mobile devices through the use of different tools and social media platforms such as Facebook, Twitter, and WhatsApp. The utilization of such platforms has helped instructors in delivering their lectures, interacting with students, and even evaluating student learning outcomes. The adoption of social media tools with mobile educational technology has been instrumental in delivering education successfully to some six million students in Saudi Arabia. ${ }^{10}$

Higher education assessment methods also have been modi-

Significance for public health

Universities in Saudi Arabia, like many international universities, have expended great effort to change the practices of educators and students when shifting the entire educational system from the traditional face-to-face education model to distance learning in response to the current global health crisis. In general, online learning has been widely discussed by researchers and proved to be a helpful tool in so many aspects. However, online learning could be affected by the nature of the educational programs. Interior Design programs, for example, rely primarily on practical courses such as design, technical, and drafting studios, which may prove more challenging to offer online than theoretical courses. Therefore, investigation of interior design students' perceptions about completion of their courses online during the COVID-19 pandemic is significant for the development of strategies to overcome issues and improve the online learning experience. 
fied to fit the new teaching strategies. Five different options have been provided to students as alternative methods to the traditional paper exam. The first option is a summative assessment/exam which includes essay, open-book exam, production of an artifact, and an E-portfolio; the second option is oral exam, only applicable to classes with small enrollment; the third option is micro teaching, whereby the flipped class strategy is implemented and students deliver lessons as though they are teachers; the fourth option is a student podcast, whereby students can submit a podcast uploaded on any media platform; and the fifth option is a simulation, whereby students examine data presented remotely and then interact and comment. The assessment strategy employed will vary with the nature of the course and the instructor's judgment as to the most effective means to evaluate student achievement of learning outcomes. Adoption of the distance-learning strategy during risks and pandemics has been implemented in the past. For example, similar strategies were used during the H1N1 outbreak, when more than 50 international universities adopted online learning as an alternative solution. ${ }^{11}$ Distance learning during that outbreak had a positive role in limiting the spread of the virus and continuing the learning process successfully. ${ }^{11,12}$ Additionally, distance learning as a topic is not new to the education field, and many studies have investigated its effects on student outcomes and performance, and reported student preferences. ${ }^{13}$ However, the abrupt transition has had its own impact on students, instructors and the whole educational process, especially in programs that are not used to delivering courses remotely such as interior design. Interior design students in Saudi Arabia typically pursue on-campus education, so the transitioning of all classes to online formats during the pandemic constitutes a new approach. Therefore, investigating interior design students' perceptions about completing their courses online during the Covid-19 outbreak is significant for the development of strategies to identify and overcome issues and improve the online learning experience. The present study discusses the advantages and challenges of implementing the distance-learning model in both theoretical and practical courses in the Interior Design program at a university in Saudi Arabia.

\section{Distance-learning approaches}

Distance learning has been defined as any learning process that separates students from educators whether by time or place, whereby various sorts of technology (such as video, audio, and computer technologies) are utilized to achieve learning goals. ${ }^{14}$ Asynchronous and synchronous are two distinct communication approaches of distance learning models. ${ }^{14,15}$ Asynchronous communication means that students are liberated from schedules, accessing their course materials at a time and place they prefer, through websites, dash/blackboard, broadcasts, and computer software. ${ }^{14}$ In this type, students have flexible time and can take the class from any location, an advantage that allows students to organize their schedules according to their own convenience. Synchronous communication, on the other hand, is the pre-scheduled form of distance learning, according to which the educator sets a time to meet and interact with students even if they are separated geographically. ${ }^{14}$ This approach, which increases learning effectiveness over in-person learning, facilitates student-student or student-educator interaction by arrangement of one-on-one dialogues or group projects. Types of education that focus on communication with others and collaboration on group projects may enhance and help implement learning strategies such as case study analysis and critical thinking. ${ }^{16}$ In general, these two approaches have been widely discussed in higher education studies, according to the roles both approaches play in distance learning and the extent to which they are efficient and effective for students. ${ }^{15}$ One study finds that, although students and professors gave high ratings to both asynchronous and synchronous approaches, the asynchronous approach was preferable to both students and instructors compared to the synchronous. ${ }^{15}$ However, it was concluded that both approaches should be used in the educational process to exploit benefits from each. Yamagata-Lynch had a similar conclusion: namely, that the asynchronous method should be complemented with the synchronous in order to enhance the connection and communication between students and peers and also between students and instructors. ${ }^{17}$

\section{Students' perceptions about distance-learning}

In general, online learning has been widely discussed by researchers, including student perceptions. Findings proved that distance learning is a helpful tool in terms of reducing tuition cost, promoting learning flexibility, ${ }^{9}$ promoting education sustainability, ${ }^{13,18}$ enhancing effective learning, and increasing student enrollment. ${ }^{19,20}$ Educators who implemented a similar strategy identified the advantages of distance learning for enhancing teaching quality and improving student learning outcomes as well. ${ }^{21}$ Well-designed and articulated online courses can provide a new means of distance interaction and participation that affects student performance positively. ${ }^{19,22}$ Another study confirmed that implementing a distance-learning approach using social media platforms provides a variety of learning activities that students can participate in, enjoy, or contribute to. ${ }^{23}$ However, due to the rapid shift from traditional learning to online learning during the COVID-19 pandemic, both educators and students faced many challenges. These challenges involved the availability and quality of the IT infrastructure, familiarity with distance learning, ${ }^{24}$ tools and techniques, ${ }^{25}$ and educators' and students' digital skills. ${ }^{24}$ The transition to online learning happened suddenly, and many educators as well as students were neither practically nor emotionally prepared. For many courses, the topics, assignments, and exams were first designed for traditional classes on campus; however, after suspension of face-to-face traditional learning, all of these plans had to be modified to accommodate the new learning strategy. To foster the new teaching approach, administrators, information technology staff, faculty and students must work together to improve the quality and to enhance the effectiveness of the distance learning process. ${ }^{9,26}$ One thing that can be beneficial is to guide students through orientations, written guidelines, and workshops, ${ }^{27}$ in order to familiarize students with the new learning approach. Awareness of the electronic resources available to them can also help students cope with the e-learning approach. ${ }^{9}$ The online courses themselves have to be examined continually to ensure quality. ${ }^{28}$ According to one study, 9 "Each part of the course needs to be evaluated using a formative approach before placing it online" (p.782). A pilot test can be done to ensure the effectiveness of the online course or software provided and anticipate any issue that may occur.

Online learning could be affected by the nature of the educational programs as well. In the Interior Design program, for example, theoretical courses are offered that lend themselves to distance learning. A study showed that online learning, which has many advantages in facilitating communication between students, proved to be useful and beneficial for interior design students in terms of enhancing their collaboration in the non-studio course. ${ }^{29}$ However, the Interior Design program relies primarily on practical courses such as design, technical, and drafting studios, which may prove more challenging to handle online. Although the integration of additional technology in the studio and practical courses has been discussed in the past, ${ }^{30}$ the implementation of such a strategy is still unfamiliar and not widely discussed by researchers. ${ }^{31}$ One 
of the few studies that investigated online learning in the studio course revealed that students tend to prefer face-to-face learning and find it more effective in the studio courses than online learning. ${ }^{31}$ Another study noted that educators as well are more reluctant to implement the distance learning model in their courses, voicing their concern about changing the traditional institutional strategies and the number of students per classroom. ${ }^{14}$

\section{Impact of COVID-19, distance learning, and other fac- tors on students' wellbeing}

During the COVID-19 outbreak, students were prohibited from going to school or visiting any public places. The pressure was greater yet for international students unable to travel to their home countries due to the closing of international airports. Even those students with official permission to travel faced the stress of not knowing when the pandemic would end and when it would be possible to return and complete their education. Such restrictions, along with the need to rely on technology to such an unprecedented extent for distance learning, a new approach for some students, had a great impact on psychological wellbeing. Many studies have examined and documented the negative impact of the pandemic on students. One of the studies investigated the well-being of students at a Spanish university. ${ }^{31}$ In the study they found that more than one third of the participants (34.19\%) experienced a high level of depression, while almost one fourth of the participants $(21.34 \%)$ had a moderate to high level of depression. ${ }^{31}$ According to both results, more than half of the students $(55.53 \%)$ had symptoms of a moderate to high level of depression. ${ }^{31}$ In the same study, the anxiety level was noticeably higher among students compared to the general population. ${ }^{31}$ A study conducted in China confirmed similar results, reporting that $66.90 \%$ of the participants experienced anxiety and almost one fourth of this number $(23.80 \%)$ had a moderate to severe level of depression. ${ }^{32}$ The impact was greater if the person utilizing the technology was alone, a situation which has occurred in many cases during the pandemic especially for international students. An early study mentioned that technology can have a negative impact when a person is lonely, and such symptoms can be overcome when a person is close to friends. ${ }^{33}$ Another study conducted at a university confirmed similar results, finding that the excessive use of the internet is associated with loneliness, ${ }^{34}$ and a negative effect on self-esteem. ${ }^{35}$

Furthermore, other studies reported that one side effect of the immoderate use of internet is internet addiction. ${ }^{36-38}$ In addition to the impact of excessive use of technology on students, a number of factors can also adversely affect students' wellbeing: a family member such as a parent being infected by COVID-19,3,39 increased financial problems, especially when a family member loses a job, ${ }^{3}$ the unclear path of the learning process to potential employment, ${ }^{40,41}$ inaccurate news reporting, ${ }^{42}$ and finally, the limitation of social interaction. ${ }^{43}$ All of these factors compromise students' well-being, which in turn is reflected in their performance, motivation, and desire to learn. ${ }^{25,44,45}$

\section{Materials and Methods}

\section{Data}

The study was conducted at a private university in Saudi Arabia with students in the Interior Design program. Students in the program had experienced the transition from face-to-face learning to distance learning during the COVID-19 pandemic in all of their courses (theoretical and practical). Students spent the first seven weeks of the semester on campus, physically attending classes. After the outbreak, students continued taking their classes but virtually, through different platforms such as LMS, Google Drive, and Google Meet. In both theoretical and practical courses, instructors delivered their lectures through Google Meet and uploaded all course materials on LMS and Google Drive. Students uploaded their assignments and projects using the same resources. The students who agreed to participate in the study were ten in total $(\mathrm{N}=10)$, all of them at the senior level. The researcher was teaching five of the students in a Senior I course (ID498), which is a theoretical course, and the other five in Senior II (ID499), a practical course (studio). The participants were all volunteers and were informed about the purpose of the study and the topic of investigation. Institutional Review Board (IRB) approval was also obtained to conduct the study (PSU IRB-2020-08-0055).

\section{Methodology}

The current paper has adopted a qualitative approach for assessing the obtained data. Semi-structured interview was used to collect all the needed information regarding participants' opinions of distance learning. Accordingly, some of the main questions were prepared earlier and the rest were based on the responses of the participants to the first questions. The interview was a one-on-one type, which means that the researcher interviewed each participant separately. ${ }^{46}$ The interview method was chosen to enable the researcher to gather as much in-depth data and information as possible regarding the challenges and advantages students faced while taking their courses online. Each interview took approximately ten minutes, and centered on three main questions: i) What are the benefits of distance learning? ii) What are the challenges that students faced when switching from traditional face-to-face classes to online learning? iii) What are the recommendations for taking these courses online in the future? Out of concern for the students' health, the interviews were conducted virtually through Google Meet.

For the analysis, thematic analysis technique was adopted in the study. This type of analysis aims to review common themes and find logical interpretations for the data obtained. Categorizing and sorting data, taking notes, and coding are three different techniques used to achieve this type of analysis. ${ }^{47}$ According to these strategies, data was sorted into three main categories on the basis of the three main questions: the benefits of the distance learning in the Interior Design program; the challenges of distance learning in the Interior Design program; and recommendations for future distance learning in the Interior Design program.

\section{Results}

\section{The benefits of distance learning in the interior design program}

Overall, since they were studying on campus, students had positive feedback regarding distance learning and the use of different media platforms such as LMS, Google Drive, videos, tutorials, and so on. A student commented about her experience studying online, saying, "I do not mind it at all. It was a little bit difficult to switch from face-to-face learning but only in the beginning, then everything was fine" (IV1). Based on that positive experience, students were generally willing to try distance-learning in the future. According to one student, "Distance learning was good and had 
many advantages, and based on my experience in the semester I took my summer courses, it was OK" (IV1). Students mentioned different aspects of the distance-learning experience that led them to prefer it. These aspects were sorted into different themes, as shown in Table 1 and discussed below.

\section{More time for school tasks}

Increased time for students to spend on their tasks was one of the advantages mentioned most often by students who preferred distance learning over in-person learning. Student (IV5) stated that "the extra time taken in the break between courses on campus in addition to the time coming and going to and from school really matters. Compiling all of that time and spending it on the given tasks is much better". Additionally, prior to the transition from the face-to-face learning model, on-campus interior design students had been engaged in many activities outside the classroom to fulfill the requirements of their courses, which may have demanded a significant amount of time from students. One student mentioned that "going to the printing center to print my board sometimes takes more than half an hour, and the printed boards do not come out successfully every time" (IV4), which means that students would take one to two hours printing one board until they were satisfied with the print quality, or even more time in the case of largescale projects. The same student reported, "Sometimes I finalize my project two days before the submission to make sure that I can print on time and overcome any issue that might occur" (IV4). It would also take additional time to go to and from the printing centers, as these professional centers are usually located off campus. Although students finished the printing before class, the time spent on printing could have been utilized to finish other course assignments or work on their projects. Many similar activities involved the same issue of time loss for students. "Talking about studios, 3D-modeling and selecting actual materials all take a lot from my working time on the projects" (IV2), one student said. For example, students would usually visit furniture stores and firms for materials selection, and could spend several hours finding the right materials for their projects. In the case of distance learning, on the other hand, students were asked to submit their tasks digitally, which reduced the time wasted. One student reported, "In distance learning, all assignments and projects were shifted to soft copies, not hard copies as we used to do. That's really helped save a lot of time" (IV4). All the time that used be taken up by activities such as printing, modeling, selecting materials, and commuting to school was freed for work on tasks, assignments, and projects.

\section{Better outcomes}

Students find distance learning very helpful in enhancing their performance and increasing their productivity. According to one student (IV1), "During my working time in the classroom, sometimes I got disturbed by other students who were talking or asking questions. However, in distance learning I can concentrate more on my work without interference from anyone, which enhanced the outcomes of my tasks". Another student mentioned that "distance learning is much more comfortable and easier for me as I don't have breaks between classes, which makes me more energetic and ready to work" (IV5). Distance learning was also better for students who prefer not to work on campus. Student (IV6) stated, "I'm more productive when I work at home, as it will be at my convenience, and the distance learning really fits me". Student (IV10) corroborated the advantage of time management, saying, "Distance learning gives me more flexible time where I can arrange my time and schedule as I want. That helped me finish the semester successfully". Student (IV7) said, "I could not imagine that I would have a day's break in my schedule. When I was on campus, I had no breaks at all [meaning breaks of days, not breaks between classes], and now [with distance learning], I can manage my time and have even a day's break then come back to work more effectively". In terms of the link between student achievement with the time spent on projects, students find distance learning to be beneficial in this regard. With the reduction of the time spent at school for breaks, commuting, or even hanging out with other students, students focus more on their work and become more productive. According to student (IV9), "Studying at home help me a lot in spending more time on my projects and focusing more on the details which I didn't have time to complete when I was studying on campus".

\section{Economy}

Economy is another aspect that students take into consideration when discussing the benefits of distance learning. Dealing with course requirements is an issue that affects the economics of some students, which in turn has a great impact on the quality of their work. For studios, including senior studio, for example, students used to have two juries during the semester and then a final

Table 1. Benefits of distance learning in the Interior Design program.

\begin{tabular}{ll} 
Benefits & Reasons \\
More time for school tasks & - No time spent on commuting to school \\
& - No wasted time between classes \\
& - Nsignments and projects submitted as soft copies \\
- No time spent on transportation (going to and from places related to the activities outside classes such as printing centers) \\
Better outcomes & - No disturbance by other students \\
& - Students do not get tired because of the wasted time between classes \\
& - Flexible time to arrange schedules \\
\hline Economy & - Change of requirement from hard copies to soft copies for all tasks \\
Communication & - No additional cost for students \\
& - More meetings with instructors \\
& - More group meetings
\end{tabular}


one. For all juries, students were required to print their projects on boards and to submit a hard copy of booklets for each project. Each board could cost 100 SR, which means three hundred riyal per semester for each student without counting reprinting, booklets, 3D-modeling, material boards, and many other requirements. These costs may compromise the quality of some students' projects. Student (IV8) mentioned, "It always comes to my mind, why should we print out our projects on boards? It is costly and not environmentally friendly, as we will throw all of them out [the boards] later". When online courses were adopted, all of these requirements changed, and students were asked to submit their work digitally, which many students preferred. According to student (IV2), "I do not like always printing our work as a hard copy. I was even happier when the requirement was switched to soft copies during COVID-19".

\section{Communication}

Students find improvement in their communication skills with online learning. For example, the students innovated a new technique to communicate with each other. These students have been studying together and taking the same classes since they were freshmen. Therefore, they found it helpful to discuss virtually with each other from time to time as though they were in class. According to student (IV3), "We usually do a group meeting through WhatsApp group or Google Meet to work together sometimes or to seek opinions from classmates, the same as we used to do in class". One student (IV5) also mentioned that "sometimes I feel as if I do not have energy or enthusiasm to work, but once I see that my classmates are meeting to work [virtually] that encourages me a lot to work with them and to finish my assignments". Distance learning has also had an impact on the communication between students and their instructors. Student (IV3) mentioned that "we have flexible hours to meet our instructors. Anytime we need advice we can contact the instructors asking for a virtual meeting without waiting for the instructors' office hours as we used to do on campus". Student (IV7) also mentioned that "when we switched to online, most of our instructors were on their computers. If we send an email, instructors reply in a maximum 15 minutes, unlike on campus where instructors were always busy with their classes and did not have enough time to reply to emails immediately".

\section{Challenges that students faced after transition from traditional face-to-face classes to online learning}

Students had positive feedback regarding distance learning, but they also experienced some challenges that might affect their comfort level. According to student (IV9), "Everything was unclear in the beginning as this strategy was new to us, so we were a little bit frustrated and confused". Another student (IV7) reported, "In the beginning I received many emails from instructors explaining the new strategies, which made me stressed". Communication, technology, and changes in grade distribution were the three main challenges that students reported facing, as shown in Table 2 and discussed in the following section.

\section{Communication}

The communication between students and public audiences was an issue for students. External jurors and families were invited to attend the senior final juries. Usually those audiences come to the university and attend students' presentations and see their works in person. During the COVID-19 limitations on face-to-face interaction, all of the attendees received invitations to a virtual meeting of the final jury. At this meeting, students presented their works without any eye contact, as they could not see the attendees' faces. This lack of visual contact encouraged students to interact with their audience verbally, which is not always sufficient. According to student (IV10), "our specialty is more about selling our ideas... Selling the ideas physically is much easier than virtually, because when you are in the front of people you can see their body language and facial expression; even you as students can do the same and play with your body language and facial expression to get the audience's attention if they get distracted. You miss all of that when you do the communication virtually". Student (IV5) added, discussing a similar issue, "When presenting projects online, audience members were not able to see the small details of our work that require a lot of time from us. It was easier to see and explain these details in the class". Student (IV8) also discussed her experience when communicating with others in the group work. The student mentioned, "In the group project, it was really hard to express the ideas to other students as they were not able to see my facial expression. It takes me less time to explain when they are with me in the class".

\section{Technical issues}

Due to the lack of preparation for the sudden shift from traditional to online learning, instructors and students were both reliant on the internet and Wi-Fi. An increase in the usage of different networks has an impact on the effectiveness of these sources. Many students experienced slowness of the internet or the freezing of certain websites. According to student (IV2), "It happened to me more than one time. My laptop was freezing in the middle of exams. Although I survived because I am used to saving my work regularly, I think if this problem happens to other students, this might be a big issue". Student (IV10) also confirmed that she had

Table 2. Challenges that students faced after transition from traditional face-to-face classes to online learning.

\begin{tabular}{|c|c|}
\hline Challenges & Reasons \\
\hline Communication & $\begin{array}{l}\text { - Too many emails } \\
\text { - Communication issues between students and public audiences } \\
\text { - } \text { No eye contact } \\
\text { - No body language and facial expression } \\
\text { - Small details of projects are not very clear and hard to explain }\end{array}$ \\
\hline Technical issues & $\begin{array}{l}\text { - Increased usage of different networks } \\
\text { - Slowness on the internet } \\
\text { - Freezing of certain websites } \\
\text { - Loss of Wi-Fi connection }\end{array}$ \\
\hline Change in grade distribution and addition of projects & $\begin{array}{l}\text { - Change of grading scale percentage for finals and classwork } \\
\text { - Change of exams to projects } \\
\text { - Addition of projects }\end{array}$ \\
\hline
\end{tabular}


similar issues during presentations and she said, "Sometimes during a presentation of one of my classmates, for example, we lost connection and I got confused, as I did not know whether the problem was from my side or on the part of the other student". The same student pointed out another technical issue: "When I tried to use the LMS, a lot of times I could not log in successfully. Out of ten times, actually one or two times it would work. I think it was freezing because many students were using the same website at the same time and this was an issue". Group work was another issue for some students, as not all students had a good Wi-Fi and internet connection in their homes. Student (IV8) noted that "sometimes in the group work, a student or two had an issue with their Wi-Fi connection, which really affected the progress of the work. When I work individually, I do not experience this issue".

\section{Grade distribution and project changing}

Changing the grade distribution of the assignments and finals was an issue for students. On campus, the total grade was out of 100 (60 distributed between majors and assignments and 40 for the finals). After the pandemic, this grade distribution was changed to 80 for the classwork, including assignments and mid-term exams, and only 20 for the finals. With this change, instructors were required to modify their class work activities (whether by adding more projects or modifying the grades) and to change finals to fit the new criteria. Student (IV8) stated, "We had more projects during that semester, as many exams had been changed to projects". Student (IV1) also said, "When the grade distribution changed, we had new types of projects. We had a lot of things to do and that required more time from us".

\section{Recommendations}

\section{Distance vs on-campus learning}

Students offered several recommendations for future distance learning in the Interior Design program. Some of the recommendations were that students be on campus even for short times and fewer days. One of the suggestions was to schedule a one-on-one meeting with the instructor, especially in the practical courses. According to student (IV5), "It would be much better to see the instructor face-to-face and seek her advice, even if we could arrange individual meetings in her office". Other students also suggested taking exams on campus. Student (IV10) said, "I suggest visiting campus regularly even if once or twice per semester for final presentations and exams, so students do not rely only on distance learning and forget the routine of going to school". Student (IV2) also said, "Because of the technical issue that I had during my exam, I suggest taking exams on campus. In case of any issue on my computer, I have a hard copy also". On this topic, student (IV8) also said, "I would like to have juries on campus. It is really important to see the expression of the instructors and jurors about my work". Several students suggested taking all classes remotely, but with different teaching techniques. For example, Student (IV5) said, "For the practical courses, instructors can make tutorials and upload them on YouTube, so the materials will be accessible to all students, especially the freshman students who really need to learn all the basics of design". Student (IV4) also suggested that scheduling more virtual meetings with students outside of the class time would be helpful in distance learning (Table 3).

\section{Projects vs exams}

In terms of the type of assignments, many students prefer exams over projects in theoretical courses and suggested having exams on campus as they used to have. Student (IV4) said, "When we had all of these projects, I wasn't sure that I would be able to finish all of them on time or not". Another student commented, "I do not have an issue with the practical courses. Issues occurred in the theoretical courses when exams were changed to projects. Most of the time was allocated to working on the projects, not to gaining knowledge from the instructor as we are supposed to do" (IV8). Student (IV6) said, "I liked studying the practical courses online and I had no issue with that. But things did not work the same in theoretical courses. In the lighting course for example, exams were changed to projects, which take more time and effort from me. I like to have exams instead". Only one student liked the change in the theoretical courses from exams to projects. Student (IV7) mentioned, "I was happy to take the theoretical courses online and I was even happier to do projects rather than exams, as I am not good at memorizing" (Table 3).

\section{Discussion}

During the COVID-19 confinement, universities in Saudi Arabia shifted their entire educational model to distance learning. The rapidly prepared shift in a program such as Interior Design impacted students both positively and negatively in different ways. From the discussion with senior interior design students, some benefits of distance learning emerged. Better achievement of learning outcomes was one of the benefits students mentioned. According to many students, distance learning has enhanced their performance and productivity. The same findings were obtained by many previous studies. In a report done by Silva et al., distance learning students achieved better results in Brazil's National Examination of Student Performance (ENADE) compared to their peers who followed the traditional learning model. ${ }^{48}$ Another study confirmed similar results, concluding that sometimes distance learning was even more effective for students than face-to-face learning. ${ }^{49}$ Some of these results are due to the time students allocate to focus on their assignments. As students mentioned, in distance learning, the time ordinarily spent on commuting or visiting different locations to fulfill some of their class requirements, devoted to greater focus on their work. Reducing the financial

Table 3. Recommendations for online interior design courses in the future.

\begin{tabular}{ll} 
Recommendations & Explanations \\
Distance $v$ s in-campus learning & - Use of hybrid teaching method \\
& - Inclusion of one-on-one meeting with the instructor (in person) \\
Projects $v$ s exams & - Taking finals on campus \\
& - Additional tutorials related to tasks required in practical courses \\
\hline
\end{tabular}


costs of study was another advantage for students. The change in many submission requirements from hard to soft copies was preferable for many students, who expressed concern about spending money on printed materials only to be discarded by the end of the semester. Although this type of reduction in cost was rarely discussed in studies, other cost issues such as tuition have been addressed in many previous studies. Distance learning can be a good choice for learners who are seeking more flexible time and a more affordable education. ${ }^{50}$ Improvement in the use of communication technology was another benefit of taking courses online. Students used different media sources such as WhatsApp and Google Meet to communicate with each other even outside the time of their classes, whether virtually or by text, seeking others' opinions and suggestions. ${ }^{13}$ In this process, students adopted a primarily synchronous approach as they scheduled time to meet. According to a study, the synchronous learning method can work well to enhance different sorts of social interaction. ${ }^{15}$ Students also experienced improvement in their communication skills using an asynchronous learning method as they were able to schedule their time, access the needed class materials, and complete assignments remotely. ${ }^{51}$ Dos Santos and Cechinel noted in their study that this type of learning is more suitable for task-oriented communication. ${ }^{15}$ Although communication was beneficial for many students, the same students experienced some issues in another area of communication. The lack of in-person contact affected students, mostly during juries. Students mentioned that they were less comfortable presenting their final projects without seeing the facial expressions and body language of others. Another problem was posed by the technical issues, which has been discussed in many studies. ${ }^{24}$ Students stated that during presentations and exams, their laptops were sometimes not working efficiently, and internet connection was lost at other times, which made the students frustrated when they were already under pressure. Therefore, students expressed a preference for the hybrid learning method, or at least for having their exams, juries, and presentations on campus. Many studies confirmed the need for implementing both the traditional learning model with distance learning. Dos Santos and Cechinel conducted a study that involved students from different courses. ${ }^{15}$ The participants of this study confirmed the need for complementing distance learning with traditional face-to-face learning. ${ }^{15}$ The authors found that, compared to more experienced students, students with less experience tended to prefer face-to-face learning. ${ }^{15}$ The same findings were obtained in the current study: students speculated that if they had been freshman, they would have experienced more challenges with distance learning and would have needed to rely on traditional face-to- face learning (IV1, IV4, and IV 10). The last issue that students discussed was change in grade distribution and assignment types. Due to such changes, students reported that they had too many projects, as most exams had been changed to projects, which added more pressure for students. Although students faced this issue during the semester of the switch, this problem may not occur again. The Ministry of Education in Saudi Arabia has a clear picture now regarding the pandemic and a defined direction for future educational strategies. Accordingly, all class requirements, including grade distribution and type of assessment will be spelled out clearly for all theoretical and practical courses.

\section{Limitations and Recommendations}

Application of the distance-learning model in programs that have many practical courses has rarely been discussed. Additional in-depth studies are recommended to identify and compare the issues students face in both theoretical and practical courses. Further, this study only investigated student perceptions of dis- tance learning with a focus on senior interior design students. During the interview, many of them expressed concern for students on lower levels of study with less experience and knowledge regarding different design programs. Therefore, future study investigating the perceptions of interior design students from the four different levels (freshmen, sophomore, junior, and senior) is highly recommended.

\section{Conclusions}

Distance education is one of the strategies adopted in education and its usefulness has been proved in many studies. The need to adopt such a strategy has increased during the COVID-19 global health crisis as an alternative method to traditional education. Students and faculty in different locations can interact, communicate, and share knowledge. Numerous learning benefits and challenges have been discussed in many studies, but the main focus of study has been distance learning in theory-based education. Practical courses such as those offered in interior design programs have been traditionally taught on campus. Therefore, transition of practical classes to an online format during the pandemic offers a unique opportunity to examine the benefits and challenges of this educational model to students. The findings about student perceptions and experiences in this transition revealed many advantages of using the distance-learning approach for practical courses and highlighted some of the challenges. Such investigation can help improve the course quality, which in turn will reflect on student performance and outcomes.

Correspondence: Samaher Fallatah, Department of Interior Design Engineering, Prince Sultan University, Riyadh, Saudi Arabia.

E-mail: sfallatah@psu.edu.sa

Key words: Distance learning; interior design; COVID-19; higher education.

Acknowledgments: I would like to thank interior design students who were ready to extend a helping hand whenever I asked and to express my appreciation to them for their collaboration. Without them, I would not have been able to complete this research.

Conflict of interest: The author declares no conflict of interest.

Ethics approval and consent to participate: Institutional Review Board (IRB) approval was obtained to conduct the study (PSU IRB2020-08-0055).

Consent for publication: The aim of the study was explained to the participants and they all had signed a written informed consent to the terms of participation in the study.

Availability of data and materials: Data stored and will be available upon request.

Received for publication: 27 August 2020.

Accepted for publication: 5 December 2020 .

oCopyright: the Author(s), 2021

Licensee PAGEPress, Italy

Journal of Public Health Research 2020; 9(s1)1914

doi:10.4081/jphr.2020.1914

This work is licensed under a Creative Commons Attribution

NonCommercial 4.0 License (CC BY-NC 4.0). 


\section{References}

1. Naser AY, Dahmash EZ, Al-Rousan R, et al. Mental health status of the general population, healthcare professionals, and university students during 2019 coronavirus disease outbreak in Jordan: A cross-sectional study. Brain Behavior 2020;10:113.

2. Krishnamurthy S. The future of business education: A commentary in the shadow of the Covid-19 pandemic. J Bus Res 2020;117;1-5.

3. Sundarasen S, Chinna K, Kamaludin K, et al. Psychological Impact of COVID-19 and Lockdown among University Students in Malaysia: Implications and Policy Recommendations. Int J Environ Res Public Health 2020;17: 6206.

4. World Health Organization. Coronavirus disease 2019 (COVID-19): situation report, 82.

5. Ana A, Minghat AD, Purnawarman P, et al. Students' Perceptions of the Twists and Turns of E-learning in the Midst of the Covid 19 Outbreak. Romanian J Multidim Educ 2020;12:15-26.

6. Carolan C, Davies CL, Crookes P, et al. COVID 19: Disruptive impacts and transformative opportunities in undergraduate nurse education. Nurse Educ Pract 2020;46:102807.

7. Ministry of Education, Kingdom of Saudi Arabia. Leading efforts to combat coronavirus pandemic. Accessed: August 14, 2020. Available from: https://iite.unesco.org/wpcontent/uploads/2020/10/The-Saudi-MOE-Leading-Efforts-toCombat-Coronavirus-Pandemic-COVID-19.pdf

8. Ministry of Education, Kingdom of Saudi Arabia. Leading efforts to combat coronavirus pandemic. Accessed: August 14, 2020. Available from: https://iite.unesco.org/wpcontent/uploads/2020/10/The-Saudi-MOE-Leading-Efforts-toCombat-Coronavirus-Pandemic-COVID-19.pdf

9. Al-Mala AH. Student perceptions of quality e-learning: An analytical case study of a two-year public community college in Virginia, United Sates of America. Dirasat Educ Sci 2007;34:781-91.

10. Saudi Press Agency. The Ministry of Education is facing the conditions of "Corona" and ends its school year with success, achieving unprecedented numbers in distance education. 2020. Accessed: August 23, 2020. Available from: https://www. spa.gov.sa/viewfullstory.php?lang=ar\&newsid $=2087174$

11. Meyer KA, Wilson JL. The role of online learning in the emergency plans of flagship institutions. Online J Distance Learning Admin 2011;14.

12. Ekmekci O, Bergstrand J. Agility in higher education: Planning for business continuity in the face of an H1N1 pandemic. SAM Adv Manag J 2010;75:20-30.

13. Hossain SF, Shan X, Nurunnabi M. Is M-Learning a Challenge? Students Attitudes Toward the Sustainable Learning and Performance. Int J e-Collab 2019;15:21-37.

14. Bender DM. Interior design faculty intentions to adopt distance education. J Interior Design 2003;29:66-81.

15. Dos Santos HL, Cechinel C. The final year project supervision in online distance learning: assessing students and faculty perceptions about communication tools. Behav Inform Technol 2019; 38:65-84.

16. Behar-Horenstein LS, Niu L. Teaching critical thinking skills in higher education: A review of the literature. J Coll Teach Learn 2011;8.

17. Yamagata-Lynch LC. Blending online asynchronous and synchronous learning. Int Rev Res Open Distance Learn 2014;15:189-212.
18. Hossain SF, Xi Z, Nurunnabi M, Anwar B. Sustainable academic performance in higher education: a mixed method approach. Interact Learn Environ 2019:1-4.

19. Sadykova G, Meskill C. The presentation of self in everyday ether: a corpus analysis of student self-tellings in online graduate courses. Online Learn 2019;23:5-21.

20. Afacan Y. Exploring the effectiveness of blended learning in interior design education. Innov Educ Teach Int 2016;53:50818.

21. Groves MM, Zemel PC. Instructional technology adoption in higher education: An action research case study. Int J Instruct Media 2000;27:57-65.

22. Shea P, Hayes S, Smith SU, et al. Online learner self-regulation: learning presence viewed through quantitative contentand social network analysis. Int Rev Res Open Distance Learn 2013; 14:427-61.

23. Hossain SF, Nurunnabi M, Hussain K, et al. Effects of varietyseeking intention by mobile phone usage on university students' academic performance. Cogent Educ 2019;6:1574692.

24. Islam MA, Rahim NAA, Liang TC, Momtaz H. Effect of demographic factors on e-learning effectiveness in a higher learning institution in Malaysia. Int Educ Studies 2011;4:11221.

25. Fariborzi E, Bakar K bt A. Factors influencing the effectiveness of courses in Iranian university e-learning centers. Int $\mathrm{J}$ Technol Knowledge Soc 2010;6:71-80.

26. Moore JC. The Sloan Consortium quality framework and the five pillars. 2005. The Sloan Consortium. Available from: http://citeseerx.ist.psu.edu/viewdoc/download;jsessionid=AB8 30A35E56121F2F18BAEDC1B347BB1?doi=10.1.1.593.450 $4 \&$ rep $=$ rep $1 \&$ type $=$ pdf

27. Cheurprakobkit S, Hale DF, Olson JN. Technicians' perceptions about Web-based courses: The University of Texas system experience. Am J Dist Educ 2002;16:245-57.

28. Margalina VM, De-Pablos-Heredero C, Montes-Botella JL. Achieving quality in e-learning through relational coordination. Stud Higher Educ 2017;42:1655-70.

29. Cho J, Cho M-H. Student perceptions and performance in online and offline collaboration in an interior design studio. Int J Technol Design Educ 2014;24:473-91.

30. Seitamaa-Hakkarainen P, Raunio AM, Raami A, et al. Computer support for collaborative designing. Int J Technol Design Educ 2001;11:181-202.

31. Odriozola-González P, Planchuelo-Gómez Á, Irurtia MJ, de Luis-García R. Psychological effects of the COVID-19 outbreak and lockdown among students and workers of a Spanish university. Psychiat Res 2020:113108.

32. Nurunnabi M, Hossain SF, Chinna K, et al. Coping strategies of students for anxiety during the COVID-19 pandemic in China: a cross-sectional study. F1000Res 2020;9:1115.

33. Valkenburg P, Peter J. Internet communication and its relation to well-being: Identifying some underlying mechanisms. Media Psychol 2007;9:43-58.

34. Moody EJ. Internet use and its relationship to loneliness. Cyberpsychol Behav 2001;4:393-401.

35. Morgan C, Cotten SR. The relationship between internet activities and depressive symptoms in a sample of college freshmen. Cyberpsychol Behav 2003;6:133-42.

36. Nalwa K, Anand AP. Internet addiction in students: a cause of concern. CyberPsychol Behavior 2003;6:653-6.

37. Greenfield DN. Psychological characteristics of compulsive internet use: A preliminary analysis. Cyberpsychol Behav 2000;5:403-12.

38. Morahan-Martin J, Schumacher P. Incidence and correlates of 
pathological internet use among college students. Comput Hum Behav 2000;16:13-29.

39. Bao Y, Sun Y, Meng S, et al. 2019-nCoV epidemic: address mental health care to empower society. Lancet 2020;395:e37e38.

40. Wang G, Zhang, Wang G, et al. Mitigate the effects of home confinement on children during the COVID-19 outbreak. Lancet 2020;395:945-7.

41. Cornine A. Reducing nursing student anxiety in the clinical setting: An integrative review. Nurs Educ Perspect 2020;41:229-34.

42. Ayittey FK, Ayittey MK, Chiwero NB, et al. Economic impacts of Wuhan 2019-nCoV on China and the world. J Med Virol 2020;92:473-5.

43. Xiao H, Zhang Y, Kong D, et al. The effects of social support on sleep quality of medical stafftreating patients with coronavirus disease 2019 (COVID-19) in January and February 2020 in China. Med Sci Monit 2020;26:e923549-1.

44. Weng C, Tsai C-C, Weng A. Social support as a neglected Elearning motivator affecting trainee's decisions of continuous intentions of usage. Australasian J Educ Technol 2015;31:17792.

45. Burcin MM, Armstrong SN, Early JO, Godwin H. Optimizing college health promotion in the digital age: Comparing per- ceived well-being, health behaviors, health education needs and preferences between college students enrolled in fully online verses campus-based programs. Health Promot Persp 2019;9:270-8.

46. Read MA, Upington D. Young children's color preferences in the interior environment. Early Childhood Educ J 2009;36:491-6.

47. Boyatzis RE. Transforming qualitative information: Thematic analysis and code development. Thousand Oaks: Sage; 1998.

48. Silva J, Oliveira F, Mourao L. [Uma comparação entre cursos a distância e presencial].[Article in Portuguese]. Proceedings of the 18 Congresso Internacional ABED de Educação a Distância "Histórias, Analiticas e Pensamento Aberto" Guias para o Futuro da EAD, São Luís - Maranhão, 2012.

49. Swan K. Learning effectiveness online: What the research tells us. Elements of quality online education, practice and direction 2003;4:13-47.

50. Andrade MS. Higher education access and success through distance English language learning. Athens J Educ 2014;1: 211-21.

51. Graham CR. Blended learning systems. In: Bonk JB, Graham $\mathrm{CR}$, editors. The handbook of blended learning: Global perspectives, local designs. Pfeiffer \& Co.; 2006. p. 3-21. 